\title{
Response of Florida citrus growers to the freezes of the 1980s
}

\author{
Kathleen A. Miller \\ National Center for Atmospheric Research*, PO Box 3000, Boulder, Colorado 80307, USA
}

\begin{abstract}
The decade of the 1980s brought a set of severe freezes to Central Florida, killing many of the state's citrus trees. The reactions of Florida's citrus growers to these freezes suggest that the experience of extreme climate events induces adjustments in risk-hedging strategies. Replanting patterns and changes in the varietal mix are found to be consistent with a portfolio model of investment behavior if it is assumed that growers' climate expectations have been updated in response to the recent freezes. Orange growers now appear to perceive an increased risk of freeze damage in those areas that were heavily affected by these events. This suggests that climate expectations and investment patterns will tend to evolve in response to changes in the frequency of extreme climate events brought about by global climate change.
\end{abstract}

\section{INTRODUCTION}

For citrus growers in the heart of Florida's citrus belt, the decade of the 1980 s was the most devastating period in nearly a century. As the decade began, Florida's citrus industry had just recovered from the effects of a serious freeze in January 1977 that sharply reduced orange production for the following 2 seasons. During the $1979 / 80$ season, Florida orange production recovered to reach an all-time high of 9.3 million tons (Florida Crop and Livestock Reporting Service 1987). Then in January 1981, central Florida was hit by the first in a set of severe freezes that dwarfed the importance of the 1977 freeze. (See Fig. 1 for the distribution of Florida orange acreage prior to these freezes.)

Freezing temperatures affected a large portion of Florida's citrus growing areas in January 1981, January 1982, December 1983, January 1985, February 1989 and December 1989. While the full effects of the December 1989 freeze cannot yet be determined, in some areas it appears to have been the worst freeze of the century, killing groves that had managed to survive the very destructive freezes of 1983 and 1985 (Florida Citrus Mutual Triangle 1990).

Prior to the December 1989 freeze, the 2 most serious of Florida's recent freezes occurred in December 1983

\footnotetext{
- The National Center for Atmospheric Research is sponsored by the National Science Foundation
}

and January 1985. Together, they are estimated to have killed approximately one third of the state's commercial citrus trees. In doliar terms, the capital loss to Florida's grove owners appears to have been on the order of $\$ 2$ billion. The heaviest losses were incurred in the northern and northwestern portions of the citrus belt, where several counties experienced a nearly complete loss of their commercial citrus trees (Fig. 2). Lake County, which had the second largest citrus acreage in the state at the beginning of 1983 , is estimated to have lost approximately 9 out of 10 of its commercial citrus trees as a result of these 2 freezes.

Although moderate freezes frequently affect portions of Florida's citrus crop, it had been nearly a century since a similar pattern of recurring severe tree-killing freezes had affected Florida's citrus industry. A similar series of freezes during the 1890s destroyed most of Florida's citrus trees. However, it is difficult to compare these 2 anomalous periods because, during the late 19 th century, the commercial citrus industry was located much further north than had been the case just prior to the freezes of the 1980 s (Florida Crop and Livestock Reporting Service undated, Brey 1985).

The 1980s were anomalous, in the sense that damaging cold temperature occurred far more frequently than growers might have expected on the basis of experience over the previous $30 \mathrm{yr}$. We cannot directly observe the effects of such an anomalous period on the 


\section{FLORIDA}

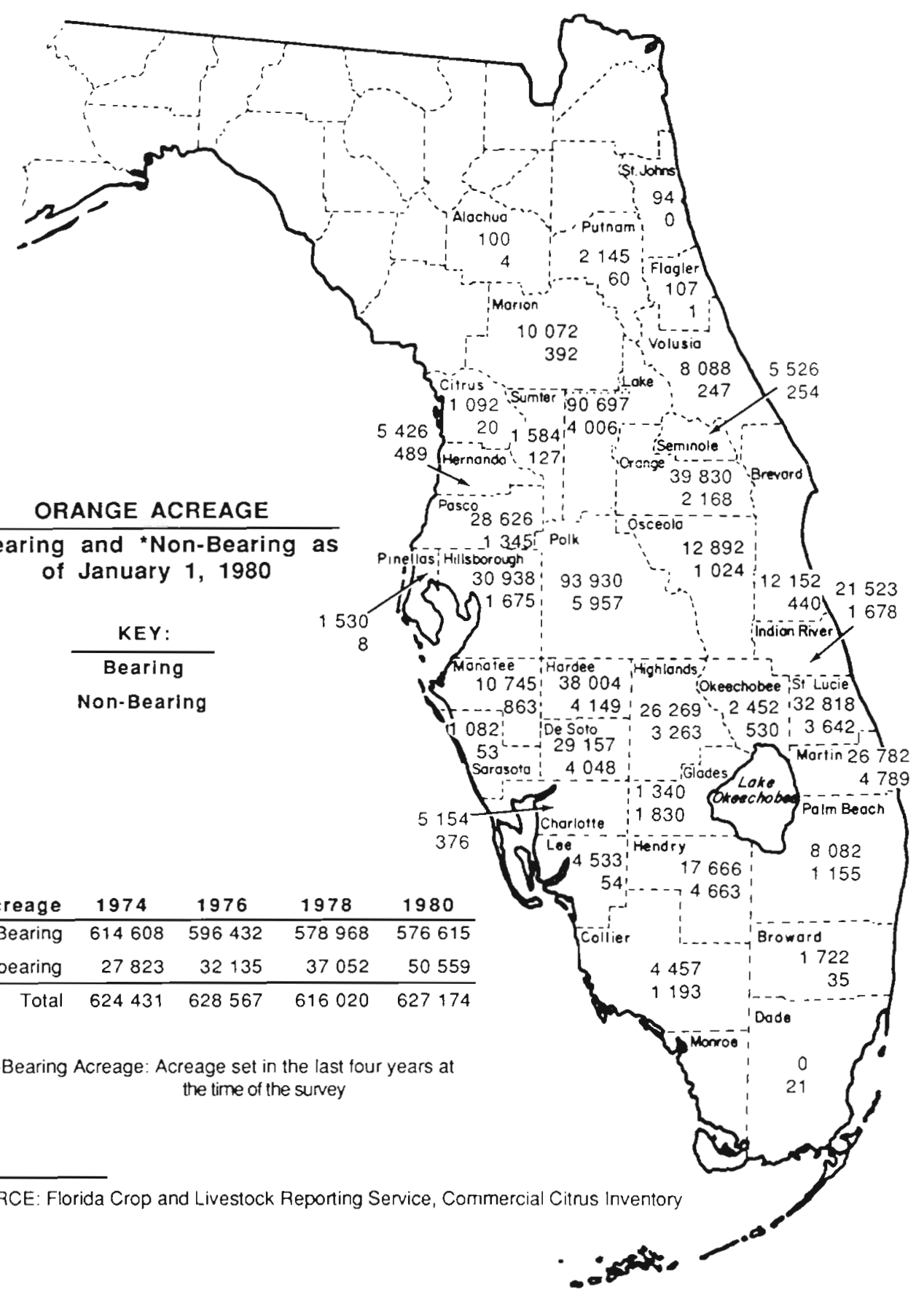

Fig. 1. Florida acreage in oranges prior to recent freezes. (No data are reported for counties without listed values)

climate expectations of a population of individuals engaged in a climate-sensitive activity. However, changes in the risk-hedging strategies of Florida's citrus growers suggest that their perceptions of freeze risks have been altered by recent experience.

The marked southward migration of new planting activity (see Fig. 3), changes in the mix of orange varieties in newly replanted groves, and the introduction of new cultural practices in areas that had been heavily affected by the freezes suggest that Florida growers are now more wary of the risk of freeze damage than had been the case prior to this anomalous period. It cannot be objectively determined if the climate of central Florida has actually changed. However, 


\section{FLORIDA}

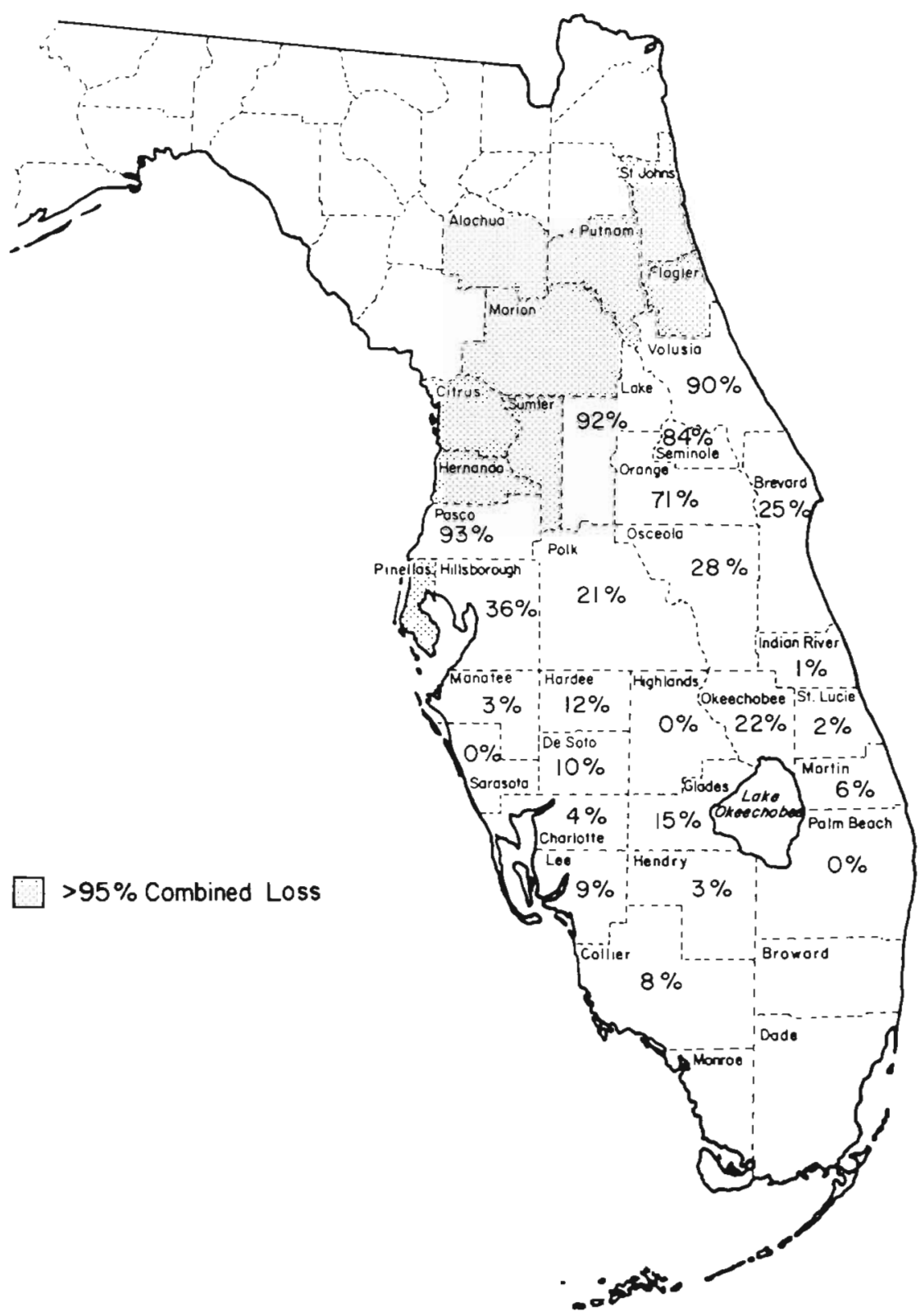

Fig. 2. Apparent freeze-related losses 1982 to 1986; percentages loss of orange trees in commercial groves in excess of assumed $2 \%$ normal attrition. (Data are no longer reported separately for the counties listed as suffering a $>95 \%$ combined loss)

citrus growers appear to be hedging their reinvestment activity in a way that suggests that they perceive an increased probability of freezes in the former heart of the citrus-growing region.

Of course, this is not the only factor affecting the pattern of reinvestment in Florida's severely freezedamaged citrus industry. Other factors include increasing urbanization in some portions of the state and increasing competition from the expanding Brazilian citrus industry. While the latter can be seen as contributing to the reduction in citrus investments in Florida's more northerly citrus counties, it cannot ex- plain the rapid expansion of citrus acreage further to the south.

The initial distribution of citrus growing activity in Florida, as well as replanting patterns following the recent freeze shocks, can be seen as consistent with a simple portfolio model of growers' investment behavior, particularly if growers are assumed to update their climate expectations in response to recent climatic events. The application of such a model to Florida's orange growers will be described in the following sections of this paper. Tests of the implications of the model will be presented, the results of which tend to support 


\section{FLORIDA}

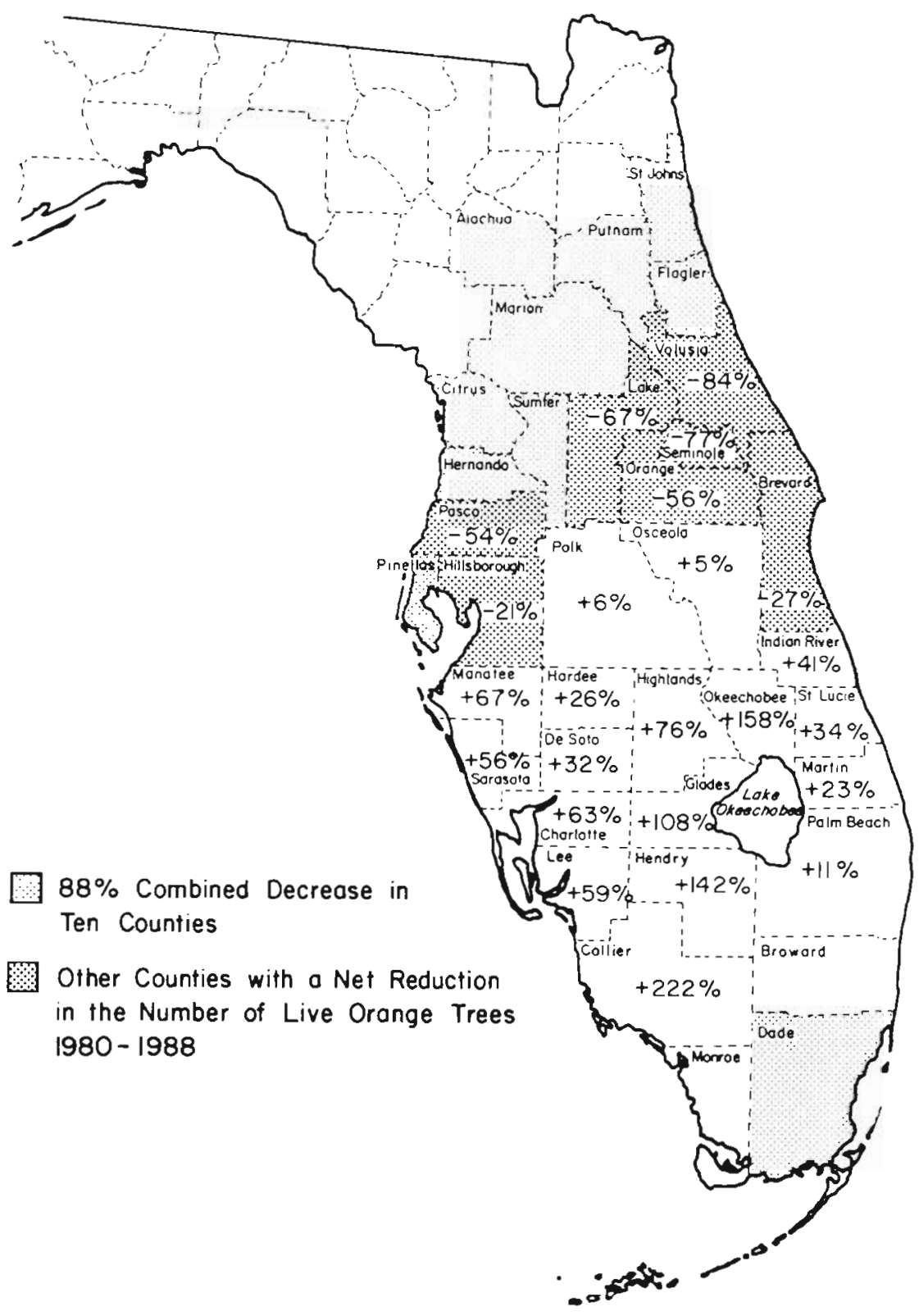

Fig. 3. Percentage change in total number of live orange trees in commercial groves 1980 to 1988, including newly planted trees. (The 'Commercial Citrus Inventory' now lists grouped data for the 10 counties experiencing an $88 \%$ combined decrease) the model's applicability. This study focuses on orange growing because of the relative importance of oranges in Florida's citrus industry and because oranges were heavily affected by the recent freeze events.

\section{FLORIDA ORANGES AND ADJUSTMENTS TO FREEZE RISKS}

All but a small portion of Florida's oranges are processed into frozen concentrated orange juice (FCOJ) and other processed products. While oranges are also produced in California and Arizona, most of that fruit is sold on the fresh market. Florida accounts for ca $90 \%$ of US production of FCOJ (Florida Agricultural Statistics Service 1987). In recent years, Florida's major competitor in the industry has been Brazil. Brazilian exports of FCOJ began in 1963 and grew very rapidly during the 1980 s. Brazil's production now exceeds that of Florida (US International Trade Commission 1983, Gunter \& Fairchild 1985, Miller \& Glantz 1988).

Freeze risks have long been an important factor influencing the location and organisation of orange 
growing activity in Florida. While freezes of the severity of those of 1983, 1985 and December 1989 are extremely rare events, freezes of sufficient severity to damage fruit, blossoms and new growth and to kill trees planted in relatively risky 'cold pockets' are a rather common occurrence in much of Florida's traditional citrus-growing region. Since the beginning of the century, ca 50 freezes of varying intensities have been recorded in Florida's major commercial citrus areas (Florida Crop and Livestock Reporting Service undated, 1988). While it is generally true that freeze risks diminish as one moves southeastward along the Florida peninsula, the choice of grove location in response to this risk is not as trivial as one might suppose. Orange growing, in particular, has traditionally been concentrated in the center of the state, along the Central Ridge rather than in more southerly and less freeze-prone locations. The Central Ridge has been a favored location because other environmental conditions, including well-drained sandy soils, have traditionally resulted in higher average yields, lower land preparation costs and a lower incidence of some diseases than could be expected with groves planted on the wet, heavy soils of southern Florida. Florida's geography thus inherently faces orange growers with a risk-return tradeoff.

It appears that diversification has been a common method of adapting to this situation. Diversification strategies might include the ownership of groves in multiple locations, the selection of an appropriate mix of orange varieties, and the derivation of income from other sources. Individual citrus acreages tend to be relatively small throughout the state, most frequently less than 50 acres (20 ha), and generally somewhat smaller in the northern growing areas than further to the south. It has also been common for grove owners to derive a substantial portion of their income from other agricultural or non-agricultural activities (Florida Grower and Rancher 1986).

In Lake County, which is located near the northern end of the Central Ridge, it is common for grove owners to live away from their groves, sometimes in nearby towns where they may hold other jobs. Some groves are owned by out-of-state parties and many owners contract with local grove management companies for all harvesting, pruning, and other grove maintenance services. Despite the fact that the tax-shelter advantages of owning a citrus grove have been greatly reduced over the years as a result of tax reforms (Powe \& Langham 1980, Brey 1985), it is not uncommon for groves to be owned by wealthy professionals and investors. The relatively risky but potentially lucrative nature of citrus groves in north-central Florida makes them an attractive investment for such individuals. Furthermore, the fact that routine operation and man- agement activities can readily be carried out by professional custom management companies makes citrus groves more attractive to absentee owners than other types of agricultural investments which might require more constant managerial attention.

In much of central Florida, where there are numerous lakes and rolling terrain, some degree of diversification by location can be achieved within the space of a few miles. Areas in close proximity to one of the larger lakes in the region tend to remain considerably warmer during freeze events than locations a few miles away. The lake effect is particularly strong just to the southeast of a sizeable lake because the prevailing wind direction is from the northwest during advective freeze events. Such locations are therefore especially favored for citrus production. In the more common radiative freezes, low-lying land becomes considerably colder than land on a slope or on a ridge top, but north-facing slopes and ridge tops are particularly at risk during windy advective freezes such as the first nights of the 1983, 1985 and 1989 events. Low-lying land that is not protected by the lake effect is commonly referred to as a 'cold pocket', and is much less likely to be planted with citrus than more favorable locations nearby. However, growers have sometimes gambled on extending their plantings into known cold pockets.

Varietal diversification is another strategy that has been commonly adopted by orange growers in freezeprone locations. Valencia oranges, which are harvested in the spring, typically command the highest prices from processors because they are sweeter, juicier and have better juice color than the varieties ripening earlier in the year (Brey 1985, Florida Agricultural Statistics Service 1987). However, Valencias are much more likely to be damaged by freezing temperatures than the early and mid-season varieties. The harvest of early varieties such as Hamlins is generally completed and the harvest of mid-season varieties is well under way before freezing temperatures are likely to occur. Valencia trees may also be somewhat less cold-tolerant, and thus more prone to damage and freeze-kill than the trees of earlier-bearing varieties (Brey 1985).

Thus, even prior to the recent severe freezes, there was a distinct north-to-south gradient in the proportion of Valencias to earlier varieties in Florida orange groves. Referring to the period 1965 to 1980, Brey (1985) notes that: 'Almost all northern counties (north of a line running roughly from Pinellas County on the west coast to Brevard County on the east coast) have fifty percent or more of their acreage planted in the pre-frost harvested varieties. .. 'Valencia' oranges are planted in at least limited quantities everywhere regardless of freeze risk. The southern, less cold areas have the greatest percentage of 'Valencias'.'

Following the devastating freezes of 1983 and 1985 , 
growers in heavily freeze-affected counties appear to have readjusted this varietal balance in favor of the lower-valued but less freeze-susceptible early varieties in their newly replanted groves. This shift in varietal proportions is predicted by a simple portfolio model, if it is assumed that the freeze events have caused an increase in the perceived probability of freezes, and thus in the relative riskiness of Valencia oranges, in the minds of these land owners.

As an example of such a change in perceived probabilities, we can consider the case of a hypothetical individual located at St. Leo in Pasco County. If that individual's expectations of the probability of freeze events had been based on their frequency during the period 1950 to 1979 , then at the beginning of 1980 , a minimum daily temperature $\leq 20^{\circ} \mathrm{F}\left(-6.7^{\circ} \mathrm{C}\right)$ would have been expected to occur in 1 out of 30 yr (a 0.03 probability), while temperatures $\leq 24^{\circ} \mathrm{F}\left(-4.4^{\circ} \mathrm{C}\right)$ would have been expected in 7 out of 30 yr (a 0.23 probability). ${ }^{1}$ Suppose that this individual's expectations of freeze probabilities are updated by merely extending the length of the record considered, as each new year is experienced, without placing any greater weight on recent years than on the years at the beginning of the record. If that is the case, then the experience of the 6 winter seasons beginning with 1980 and ending with 1985 would have caused this individual's posterior perceived probability of temperatures $\leq 20^{\circ} \mathrm{F}$ $\left(-6.7^{\circ} \mathrm{C}\right)$ to increase to 0.11 , and of temperatures $\leq$ $24^{\circ} \mathrm{F}\left(-4.4^{\circ} \mathrm{C}\right)$ to increase to $0.33 .^{2}$ Depending upon the grower's expectations about future orange prices, the opportunity cost of land, and the cost of non-land inputs, such changes in perceived freeze probabilities could be sufficient to substantially reduce the desirability of investments in orange trees, particularly of relatively freeze-susceptible varieties.

Note that this simple characterization of how a grower's freeze expectations may have changed is only one of a variety of possibilities. Alternatively, a grower may

\footnotetext{
Computations performed by Mary Downton, Environmental and Societal Impacts Group, National Center for Atmospheric Research, using minimum daily temperature records. $20^{\circ} \mathrm{F}\left(-6.7^{\circ} \mathrm{C}\right)$, if sustained for a sufficient number of hours, is roughly the temperature at which the major limbs and trunk can be killed. $24^{\circ} \mathrm{F}\left(-4.4^{\circ} \mathrm{C}\right)$ is sufficiently cold to damage fruit, blossoms and new growth and, if sustained for a sufficient number of hours, is roughly the temperature at which wood damage can commence. Note that temperature alone is a very poor predictor of damage to citrus trees Duration and the tree's state of cold hardiness, itself a function of temperatures during the weeks preceding a freeze event, are also critically important

2 During the period 1980 to 1985 , temperatures at St. Leo fell below $20^{\circ} \mathrm{F}\left(-6.7^{\circ} \mathrm{C}\right)$ on 3 occasions and below $24^{\circ} \mathrm{F}$ $\left(-4.4^{\circ} \mathrm{C}\right)$ on 5 occasions
}

place greater weight on the experience of recent years, or possibly less weight. There is a literature in hazards perception suggesting that individuals may place greater weight on recent climatic events than on the record of earlier years, simply because memories tend to fade. Taylor et al. (1988), for example, found that farmers from the Ogallala Aquifer region of the Great Plains (USA) tended to remember primarily the most severe and most recent droughts experienced. They also found that perceptions of change in the frequency of drought depended on the individual's length of experience in farming.

The purpose of the present paper is not to test alternate models of the formation of climate expectations. That cannot be done with the aggregate data available on citrus planting activities. Rather, the purpose is to determine if observed changes in this activity are consistent with an economic model of risk management if it is assumed that the recent freezes have, in some fashion, resulted in an increased perceived freeze risk. The portfolio model presented below does not, itself, address the issue of expectations formation. That is in the realm of psychology. The model does, however, predict how investment behavior will change in response to changes in perceived risks and returns.

\section{INVESTMENTS IN ORANGE GROVES: A PORTFOLIO MODEL}

If orange growers are assumed to be risk-averse investors, then standard portfolio choice theory (Markowitz 1970, Arrow 1971) implies that their investment choices will depend on the relative expected returns and risks associated with alternative investment options as well as on their individual degrees of risk aversion. Diversified portfolios will be selected if the reduction in portfolio risk resulting from diversification sufficiently compensates the individual for any reduction in expected return.

Such models have been widely employed by agricultural economists to describe optimal crop diversification strategies. Here, the question of interest is whether the observed changes in the pattern of Florida citrus plantings are consistent with the changes that would be predicted by such a portfolio model if growers' perceptions of freeze risks have, in fact, been altered by the recent freezes.

A simple characterization of the portfolia choice problem is a 2 -asset model in which one of the assets has both a higher mean (expected) return and a higher variance of returns than the other. If these returns are normally distributed and if the individual's utility function can be described as an exponential function of the form

$$
U(M)=a-b e^{-\Theta M}, \Theta>0
$$


(where utility $=U(M)$ denotes the individual's level of satisfaction and $M$ is the return on the individual's portfolio), then expected utility is:

$$
E[U(M)]=a-b e^{-\Theta E(M)}+\frac{\Theta^{2}}{2} V(M)
$$

(see Appendix for derivation; Freund 1956, Selley 1984) and maximizing Eq. [2] is equivalent to maximizing:

$$
E(M)-\gamma V(M)
$$

where $\gamma=\frac{\Theta}{2}$ and $V(M)$ is the variance about the expected value of $M$ (see Freund 1956 for this derivation). The parameter $\gamma$ increases with the degree of risk aversion.

With 2 assets,

$$
E(M)=\mu_{1} x_{1}+\mu_{2} x_{2}
$$

and

$$
V(M)=x_{1}^{2} \sigma_{1}^{2}+x_{2}^{2} \sigma_{2}^{2}+2 x_{1} x_{2} \sigma_{12},
$$

where $x_{1}=$ holdings of Asset $1 ; x_{2}=$ holdings of Asset $2 ; \mu_{1}=$ expected return on Asset $1 ; \mu_{2}=$ expected return on Asset $2 ; \sigma_{1}^{2}=$ variance of return on Asset $1 ; \sigma_{2}^{2}$ $=$ variance of return on Asset $2 ; \sigma_{12}=$ covariance of returns on Assets 1 and 2.

If $W=$ initial wealth and all wealth is assumed to be invested in some combination of the 2 assets then the Lagrangian expression to be maximized for this portfolio choice problem can be written as:

$L=$

$\mu_{1} x_{1}+\mu_{2} x_{2}-\gamma x_{1}^{2} \sigma_{1}^{2}-\gamma x_{2}^{2} \sigma_{2}^{2}-2 \gamma x_{1} x_{2} \sigma_{12}+\lambda\left(x_{1}+x_{2}-W\right)$

where

$$
x_{1}>0 ; x_{2}>0 ; x_{1}+x_{2}=W .
$$

In the present context, Valencias might be defined as the riskier asset, particularly in the more freeze-prone locations, and early and mid-season varieties as the other asset. Alternatively, a 2 -asset model can be proposed with oranges as the relatively risky, high-return asset and non-citrus investments as the other asset. In either case, we wish to examine the implications of the portfolio model for the proportion of wealth devoted to each of the assets when there is a change in the expected frequency and/or intensity of freeze events.

Changes in the expected returns and perceived risks associated with each of the assets in response to a change in climate expectations will vary according to the individual grower's location within Florida. For example, growers in north-central Florida might perceive a fall in the expected returns from Valencias relative to other oranges and from oranges relative to other investments. Under certain circumstances, they might also perceive an increase in the variance of returns from these assets. That would be the case for individuals whose fruit losses in some years are expected to be small enough for the freeze-year price increases to more than compensate for the lost fruit, while in other years the physical losses of fruit and trees are expected to overwhelm the compensating effect of higher fruit prices. Growers in southern Florida, on the other hand, might perceive an increase in the expected returns from oranges in general, and perhaps from Valencias relative to other oranges, as a result of an increase in the expected frequency and severity of freezes affecting their northern neighbors.

The direction of change in the desired proportions of Valencias to other varieties, or of oranges to other investments, can be derived by noting changes in the choice variables resulting from changes in the expected returns and variances, i.e. from the comparative statics of the above Lagrangian expression. If we define $x_{1}^{*}, x_{2}^{*}$, and $\lambda^{*}$ as the values for the $x^{\prime}$ s and the Lagrange multiplier at which utility is maximized, then we obtain the following differentiable first order identities:

$$
\begin{gathered}
\frac{\partial L}{\partial x_{1}}=\mu_{1}-2 \gamma\left[\sigma_{1}^{2} x_{1}^{*}+\sigma_{12} x_{2}^{*}\right]+\lambda^{*} \equiv 0 . \\
\frac{\partial L}{\partial x_{2}}=\mu_{2}-2 \gamma\left[\sigma_{2}^{2} x_{2}^{*}+\sigma_{12} x_{1}^{*}\right]+\lambda^{*} \equiv 0 . \\
\frac{\partial L}{\partial \lambda}=x_{1}^{*}+x_{2}^{*}-W \equiv 0 .
\end{gathered}
$$

Differentiating this set of identities with respect to the $\mu^{\prime}$ s yields:

$$
\frac{\partial x_{1}^{*}}{\partial \mu_{1}}=\frac{1}{2 \lambda\left(\sigma_{1}^{2}+\sigma_{2}^{2}-2 \sigma_{12}\right)},
$$

which must be positive by the second order conditions for a maximum.

$$
\frac{\partial x_{2}^{*}}{\partial \mu_{1}}=-\frac{\partial x_{i}^{*}}{\partial \mu_{1}} .
$$

The results for $\mu_{2}$ are analogous, so the desired proportion of $x_{1}$ to $x_{2}$ will rise as $\mu_{1}$ rises relative to $\mu_{2}$.

Differentiating with respect to the variances yields:

$$
\frac{\partial x_{1}^{*}}{\partial \sigma_{1}^{2}}=\frac{-x_{1}^{*}}{\left(\sigma_{1}^{2}+\sigma_{2}^{2}-2 \sigma_{1,2}\right)}=-\frac{\partial x_{2}^{*}}{\partial \sigma_{1}^{2}} .
$$

Since $\frac{\partial x_{1}^{*}}{\partial \sigma_{1}^{2}}$ must be negative, the desired proportion of assets devoted to $x_{1}$ will fall as $\sigma_{1}^{2}$ increases relative to $\sigma_{2}^{2}$. Again, the results for $\sigma_{2}^{2}$ are analogous

Differentiating with respect to the covariance yields:

$$
\frac{\partial x_{1}^{*}}{\partial \sigma_{12}}=\frac{\left(x_{1}^{*}-x_{2}^{*}\right)}{\left(\sigma_{1}^{2}+\sigma_{2}^{2}-2 \sigma_{12}\right)}=-\frac{\partial x_{2}^{*}}{\partial \sigma_{12}} .
$$

This result implies that increasing the covariance will increase the proportion of wealth invested in whichever asset already occupies the dominant position in the portfolio. In other words, if the individual initially found Asset 1 to be somewhat more attractive than Asset 2 and thus holds a portfolio in which $x_{1}>x_{2}$, then 
increasing the covariance will further increase that individual's holding of Asset 1 while decreasing holdings of Asset 2.

The effects of a change in total wealth on the desired portfolio balance can be found as follows:

$$
\text { Define } \begin{aligned}
y_{i}^{*} & =\frac{x_{1}^{*}}{W} \\
y_{2}^{*} & =\frac{x_{2}^{*}}{W} .
\end{aligned}
$$

Then by dividing the first order identities through by $W$ and differentiating the resulting identities with respect to $W$, one obtains:

$$
\frac{\partial y \dot{i}}{\partial W}=\frac{\frac{\left(\mu_{2}-\mu_{1}\right)}{W^{2}}}{2 \gamma\left(\sigma_{1}^{2}-\sigma_{2}^{2}-2 \sigma_{12}\right)}=-\frac{\partial y_{\dot{2}}}{\partial W} .
$$

$\frac{\partial y \underline{i}}{\partial W}$ would be negative if $x_{1}$ is the higher return land, by assumption, riskier) asset. In other words, as an individual becomes wealthier, a smaller proportion of that wealth will be invested in the relatively risky, high expected return asset.

This relationship implies that a decrease in wealth, as was experienced by many of Florida's citrus growers, would actually increase the desired weight of the riskier asset in the individual's now smaller portfolio. This result is consistent with Arrow's hypothesis of increasing relative risk aversion (Arrow 1971).

The direction of this wealth effect further implies that if orange growers decrease the desired weight of Valencias, for example, in their portfolios subsequent to a set of freezes, the change cannot be explained by their diminished wealth as a result of the freeze damage. Rather, such a change must be explained in terms of a fall in the expected returns on investments in Valencias and/or an increase in the perceived variance of those returns. As was argued above, if there is an increase in the expected frequency and severity of freezes affecting Florida's traditional orange growing areas, it would reduce the expected returns on oranges relative to other investments and Valencias relative to other varieties in the more northerly, freeze-prone locations. The model predicts that growers located in those areas would therefore reduce the proportion of their assets devoted to oranges in general, and to Valencias in particular, relative to their portfolio balances prior to the freeze damage.

In less freeze-prone locations, the model implies that higher expected orange prices, resulting from reduced production further to the north, would tend to increase the expected returns on oranges, inducing expanded plantings. This effect would be offset to the extent that increased production of Brazilian FCOJ is expected to depress prices for Florida's juice oranges. Therefore, expanding orange acreage in southern Florida suggests that growers expect some combination of reduced orange output in northem Florida and increasing demand to overwhelm the price effects of increased Brazilian production. If the relative price of Valencias is expected to increase, growers in the less freeze-prone areas might also wish to increase the proportion of their land devoted to Valencias.

It is somewhat more difficult to predict how an increase in the expected frequency and severity of freezes would affect growers' perceptions of the variability of returns across Florida's orange growing areas. However, it seems likely that any change in perceived variances would tend to reinforce the changes in portfolio composition that would be desired on the basis of the predicted changes in expected returns. ${ }^{3}$

\section{EMPIRICAL ANALYSIS OF PORTFOLIO ADJUSTMENTS}

Data from Florida's biennial 'Citrus Inventory' (Florida Crop and Livestock Reporting Service, biennial series) can be used to test the joint hypothesis that Florida's citrus growers diversify their investments across citrus varieties and other assets in a manner consistent with the portfolio choice model and that their perceptions of freeze risks have increased. The 'Citrus Inventory' records the number of live trees in Florida's citrus groves by variety and age of tree at 2 yr intervals, providing snapshots of growers' planting activities. Since relatively few trees were killed by the twentieth century freezes that occurred prior to December 1983, comparisons of orange groves as they existed in 1982 with the pattern of new planting activity following the 1983 and 1985 freezes will be used to test the implications of the above joint hypothesis. No replanting has yet been carried out following the 1989 freeze, so the effects of that event cannot be incorporated in the analysis.

\footnotetext{
3 If demand for oranges is sufficiently elastic and freezes are expected to be of the crop-damaging rather than tree-killing variety, then orange growers in northern Florida might expect an increased frequency of years with returns less than the mean. This would correspond to an increase in the weight in the left tail of the return destribution rather than a symmetrical increase in the variance. Southern Florida growers might expect an increase in the frequency of years with higher than mean prices, corresponding to an increase in the weight in the right tail of their return distribution. While such changes would entail a violation of the normality assumption underlying the simple mean-variance portfolio model, alternative mean-semivariance models imply that such changes in the weights of the tails would have the same effect on the direction of portfolio investment as the hypothesized changes in expected returns
} 
Regarding the choice of varietal mix, the portfolio model predicts that the proportion of Valencias to early and mid-season oranges should fall in areas where the risk of freeze damage is perceived to have increased. If the proportion of orange trees killed during the 1983 and 1985 freezes is used as a proxy for the change in the expected return on Valencias relative to the return on the other varieties, then the following empirical model can be proposed to test for the implied change in varietal mix:

$$
V_{1}=V_{0} \mathrm{e}^{b_{0}+b_{1} \text { (KILLPROP) }}, \quad b_{1}<0
$$

where $V_{0}=$ the initial (1982) proportion of Valencias to the early and mid-season varieties; $V_{1}=$ the proportion of Valencias among new trees planted in the postfreeze period (1985 to 1987 ); KILLPROP = the percentage of orange trees lost between the 1982 and 1986 citrus censuses in excess of assumed $2 \%$ normal annual attrition.

This functional form was selected because the dependent and independent variables are expressed as proportions. The model can be estimated as:

$$
\ln \left(\frac{V_{1}}{V_{0}}\right)=b_{0}+b_{1} \text { (KILIPROP). }
$$

The parameters $b_{0}$ and $b_{1}$ were estimated using weighted least squares ${ }^{4}$ and county-level data on live citrus trees in commercial groves, by variety and age of tree (Florida Crop and Livestock Reporting Service, biennial series). The results are reported in Table 1. The coefficient of KILLPROP, $b_{1}$, was found to be significantly negative, the predicted result. The data indicate that the proportion of Valencias to early and midseason oranges declined in all counties that lost more than $20 \%$ of their orange trees between January 1982 and January 1986. In Lake County, for example, Valencias had accounted for $43 \%$ of all orange trees prior to the 1983 freeze, while only $7 \%$ of young trees planted since 1985 are Valencias, and the remainder are earlier varieties. The proportion of Valencias increased in a few cases, notably in Palm Beach and Collier Counties in extreme southern Florida.

Since no information was available on the value of the non-citrus assets owned by Florida's orange growers, and since the adjustment of total orange acreage in an individual's portfolio may require a considerably longer period than is required to adjust varietal proportions among newly planted trees, a slightly different type of empirical model must be used to examine the possible impacts of the recent freezes on the desired volume of total investment in orange groves. The portfolio model implies that this should fall in heavily freeze-affected counties and possibly rise elsewhere, if climate expectations have changed. Let us assume that growers now have some TARGET number of orange
Table 1. Regression results. Dependent variable: $\ln \left(\frac{V_{1}}{V_{0}}\right)$; $R$-square: 0.5927 : adjusted $R$-square: 0.5750 ; total degrees of freedom: 24

\begin{tabular}{|lccc|}
\hline Variable & Coefficient & $\begin{array}{c}\text { Standard } \\
\text { error }\end{array}$ & $\begin{array}{c}t \\
\text { (Significance) }\end{array}$ \\
\hline KILLPROP & -1.825 & 0.315 & -5.786 \\
CONSTANT & -0.352 & 0.129 & $\begin{array}{c}0.0001) \\
-2.715 \\
\end{array}$ \\
& & & $(0.0124)$ \\
\hline
\end{tabular}

trees that differs from the ORIGINAL number. The difference is hypothesized to be a function of KILLPROP (as a proxy for the change in the relative expected return from oranges) and a dummy variable for rapidly growing urbanized counties (URB), where the movement of land out of citrus is likely to be strongly influenced by opportunities for development. This can be expressed as:

$$
\begin{aligned}
(\text { TARGET }- \text { ORIGINAL })= & b_{0}+b_{1} \text { KILLPROP } \\
& +b_{2} \text { URB. }
\end{aligned}
$$

The TARGET, however, is unobservable. All that can be observed is the number of newly planted trees since the freeze events. If there is an adjustment lag, this can be assumed to be some fraction of the difference between the TARGET and SURVIVING number of trees.

Define:

SURVIVING $=$ ORIGINAL - TREEKILL $=$ The number of orange trees surviving the 1983 and 1985 freeze events.

ORIGINAL = Live orange trees as of the 1982 citrus census.

TREEKILL $=$ Trees lost between the 1982 and 1986 censuses in excess of assumed $2 \%$ normal annual attrition.

NEWSETS $=$ New orange trees planted in the postfreeze period (1985 to 1987$).^{5}$

4 The weights are equal to:

$$
\frac{\text { NEWSETS } V_{1}}{1-V_{1}}+\frac{\text { ORIGINAL } V_{0}}{1-V_{0}}
$$

Weights of this form make the variance of the dependent variable independent of the variance of the explanatory variable, allowing unbiased parameter estimates

5 The data available on newly planted trees (Florida Crop and Livestock Reporting Service, biennial series) are a reliable indicator of actual planting activity only during periods unaffected by freezes, such as the 1985 to 1987 planting seasons. This is due to the fact that only surviving trees are counted in the biennial citrus census, and young trees are particularly susceptible to freeze-kill. This precludes the use of a distributed lag model to examine the dynamics of growers' investment behavior 
(The above variables are adjusted for differences in county land area, by dividing by land area.)

$\mathrm{URB}=\mathrm{A}$ dummy variable taking a value of 1 for counties with a 1986 population density greater than 300 persons per square mile (117 persons $\mathrm{km}^{-2}$ ), and zero otherwise. All 8 counties in the urbanized group are also growing rapidly, adding a minimum of 70 persons per square miles ( 27 persons $\mathrm{km}^{-2}$ ) between 1980 and $1986 .^{6}$ All of the more rural counties are adding population more slowly (Bureau of Economic and Business Research 1987).

The following model of new planting activity can be posited:

NEWSETS $=\mathrm{C}($ TARGET - SURVIVING $), 0 \leq \mathrm{C} \leq 1$

or

$\frac{\text { NEWSETS }}{\mathrm{C}}=$ (TARGET - ORIGINAL + TREEKILL).

Some manipulation and substitution into Eq. (16) yields the following equation to be estimated:

$$
\begin{gathered}
\text { NEWSETS }=\left(b_{0} \cdot C\right)+\left(b_{1} \cdot C\right) \text { KILLPROP } \\
+\left(b_{2} \cdot C\right) \text { URB }+C(\text { TREEKILL }) .
\end{gathered}
$$

$C$ is expected to be a positive number between 0 and $1, b_{1}$ and $b_{2}$ are expected to be negative and $b_{0}$ would be positive if orange prices are expected to increase, allowing growers in relatively freeze-free counties to enjoy increased relative returns on oranges.

The parameters were estimated using ordinary least squares and the results are reported in Table 2 . Since C is estimated to be significantly positive and the coefficients on the other independent variables are significant with the expected signs, these results tend to support the proposed joint hypothesis.

\section{DISCUSSION AND CONCLUSION}

The recent replanting behavior of Florida's orange growers is consistent with the hypothesis that their climate expectations have been updated as a result of experience with anomalous climatic conditions. The regression analysis suggests that orange growers in the heavily freeze-affected counties are actively modifying their varietal mix in favor of less freeze-susceptible but lower-valued varieties. Further evidence for this shift can be found by comparing the varietal mix among newly planted trees in the period just prior to the 1977 freeze with that in more recent periods. During the relatively mild period from 1973 to 1976 , Valencias accounted for ca $39 \%$ of the new orange trees planted in Lake County (then the state's largest orange-producing county). In Polk County (then second in orange
Table 2. Regression results. Dependent variable: NEWSETS $R$-square: 0.4164 : adjusted $R$-square: $0.3330 ;$ total degrees of freedom: 24

\begin{tabular}{|lccc|} 
Variable & Coefficient & $\begin{array}{c}\text { Standard } \\
\text { error }\end{array}$ & $\begin{array}{c}t \\
\text { (Significance) }\end{array}$ \\
\hline TREEKILL & 0.339 & 0.113 & $\begin{array}{c}3.009 \\
(0.0067) \\
\text { URB }\end{array}$ \\
KILLPROP & -0.521 & 0.249 & $\begin{array}{c}-2.087 \\
(0.0493) \\
-2.380\end{array}$ \\
CONSTANT & -1.040 & 0.438 & $\begin{array}{c}0.0268) \\
6.111\end{array}$ \\
& 0.982 & 0.161 & $(0.0001)$ \\
\hline
\end{tabular}

production), ca $46 \%$ of the newly planted trees were Valencias. These proportions differed little from those for the entire inventory of live trees in these counties as of 1982. The proportion of Valencias among newly planted trees appears to have dropped sharply in both counties following the 1977 freeze, never approaching the previous levels. The apparent drop was larger in Lake County, which had been more seriously affected by the freezes. Data from the most recent 'Citrus Inventory' (Florida Crop and Livestock Reporting Service, biennial series), identifies ca $7 \%$ of the trees planted in Lake County in the period 1985 to 1987 as Valencias, while the proportion so identified for Polk County is ca $10 \%$.

The regression analysis also suggests that growers in the most heavily freeze-affected counties are less inclined to plant new groves than their neighbors in counties that escaped major freeze damage. Planting activity appears to be accelerating in several counties in southern Florida. For example, in the 7 southem counties in which there were already at least 2 million orange trees by 1982, new planting had increased the number of trees by ca $63 \%$ by $1988 .^{7}$ This enthusiasm for new planting in southern Florida is consistent with any explanation for increased expected returns from orange growing in that area. For example, it could be explained by expected growth in world demand for orange juice, and therefore higher prices. However, that would not explain the pattern of replanting in north-central Florida, since the portfolio model implies that there should be a similar degree of enthusiasm for new planting in the more freeze-prone counties unless

${ }^{6}$ Counties in the urbanized group are: Brevard, Hillborough, Lee, Orange, Palm Beach, Pasco, Sarasota, and Seminole

7 These counties are: De Soto, Hardee, Hendry, Highlands, Indian River, Martin, and St. Lucie, where a total of more than 13 million new orange trees were planted between 1982 and 1987 
the recent freeze events have altered growers' climate expectations. This conclusion stems from the assumption that the land-use portfolios of northern growers had previously been well adjusted to their perceptions of the climatic risk.

The regression analysis suggests that while growers in the more northerly counties intended to replace many of the trees that were lost in the recent freezes, (according to the 1988 'Citrus Inventory') their enthusiasm for new planting was inversely related to the amount of freeze damage suffered. All of this suggests that growers in the northern counties now perceive an increased likelihood of freezes in the future. However, the fact that they were willing to replant at all implies that the weight that they placed on the particularly devastating freeze events of 1983 and 1985 was small enough to allow them to expect a positive net present value on their investments in newly planted groves. It must be remembered that the pay-back period for an orange grove is quite long because orange trees do not bear significant quantities of fruit until at least 5 yr after planting. ${ }^{8}$ A grower must expect a grove to survive at least as long as the pay-back period for the investment to be preferable to alternate uses of the land such as cattle grazing or row crops.

This case study supports the hypothesis that decision makers in this climate-sensitive industry hedge climatic risks in a manner consistent with standard portfolio theory. They also appear to update their climate expectations on the basis of recent experience. This apparent adjustment process does not, in itself, imply that decision makers place greater weight on recent climatic conditions than on those experienced in earlier years. However, it does imply that new information is in some way systematically incorporated in the formation of climate expectations.

The analysis suggests that the very severe freeze of December 1989 could, ceteris paribus, be expected to further reduce desired citrus plantings, particularly of late-fruiting varieties such as Valencias in freeze-prone portions of Florida's traditional citrus belt. It could also be expected to further increase the desirability of citrus plantings in the expanding southern citrus-growing areas.

A recent change in Federal policy may, however,

\footnotetext{
${ }^{8}$ If, for example, a new Hamlin orange grove is planted in Central Florida and it suffers no more than $2 \%$ normal annual tree mortality and if annual freeze-related fruit losses average $6 \%$, then assuming a $10 \%$ opportunity cost of capital, the payback period for this investment is roughly 14 yr prior to income tax considerations. Here, the payback period is calculated as the minimum number of years that a grove must survive in order for it to have a positive net present value. Author's computations, cost and return figures taken from Muraro \& Fairchild (1985)
}

result in considerably more replanting of citrus trees in freeze-damaged areas than landowners would have chosen in the absence of the new assistance program. The '1989 Disaster Assistance Act' and the '1989 Tree Assistance Program' (Federal Register 1989), both administered through the Federal Agricultural Stabilization and Conservation Service, offer unprecedented assistance to those Florida citrus growers suffering serious crop and tree losses as a result of the December 1989 freeze. In particular, the tree program offers grants of up to $\$ 25000$ to assist replanting on properties where more than $45 \%$ of the trees were killed. It appears that much of the groveland in north-central Florida may qualify for assistance under the program. Therefore, any further shift in the climate expectations of north-central Florida's citrus growers resulting from this latest freeze may not become apparent in their subsequent replanting activities. It should be noted, however, that the tree program is designed to encourage partial rather than total replanting. It is therefore not entirely inconsistent with growers' likely perceptions of optimal replanting strategies. Following the 1983 and 1985 freezes, Federal assistance was available to growers in the form of disaster loan programs through the Small Business Administration and the Farmers Home Administration. However, due to rapid repayment deadlines and restrictions on the use of these funds, relatively few growers applied for assistance under these programs (FmHA 1985, SBA 1985 , Miller 1988).

The results reported here also have implications for the process of economic adjustment to global warming The results suggest, for example, that as $\mathrm{CO}_{2}$ /tracegas-induced global warming results in changing local climates and in an increased frequency of anomalous climatic events, we can expect patterns of investment in climate-sensitive activities to change. The reactions of economic decision makers to their own changing climate expectations can be expected to result in a gradual adaptation of economic activities to changing climatic regimes. The fact that such adaptation can be expected to occur does not, however, imply that the social cost of climate change will be small.

One question that has not been addressed here is: how will decision makers respond to information about climate other than that gained through direct experience? For example, how might they respond to the announcement of the results of computer simulations of future climate as altered by the addition of $\mathrm{CO}_{2}$ and other trace gases? This is an important question since the results of such simulations are already being widely publicized, and it is likely that they will continue to receive considerable attention. It is not clear to what degree members of the general public understand the very large inherent uncertainties in the regional cli- 
mate change projections derived from these computer simulations. An important area for future research would therefore be an examination of responses to that type of information about future climates.

Acknowledgements. The author acknowledges the helpful comments of Richard Katz, Barbara Brown, and Mary Downton.

\section{APPENDIX}

\section{Derivation of Eq. (2)}

$$
\begin{aligned}
U(M)=a-b e^{-\Theta M}, & M \text { is normally distributed } \\
E[U(M)] & =a-b E\left(\mathrm{e}^{-\Theta M}\right) \\
& =a-b \psi(-\Theta)
\end{aligned}
$$

where $\psi$ is the moment generating function for the normal distribution.

$$
\psi(t)=\mathrm{e}^{t E(M)+t^{2} / 2 \operatorname{Var}(M)}
$$

so

$$
E[U(M)]=a-b \mathrm{e}^{-\Theta E(M)+\Theta^{2} / 2 V(M)}
$$

\section{LITERATURE CITED}

Arrow, K. J. (1971). Essays in the theory of risk-bearing. Markham, Chicago

Brey, J. A. (1985). Changing spatial pattems in Florida citriculture, 1965-1980. Ph.D. dissertation. University of Wisconsin, Madison

Bureau of Economic and Business Research (1987). Florida estimates of population April 1, 1986: states, counties and municipalities. Population Program, College of Business Administration, University of Florida, Gainesville

Federal Register (1989). 1989 Disaster Assistance Act Public Law 101-82, 54FR40369 No. 189, 10/02/89; 1989 Tree Assistance Program, 54FR47669 No. 220, 11/16/89

Florida Agricultural Statistics Service (1987). Florida agricultural statistics; citrus summary. Florida Crop and Livestock Reporting Service, Orlando

Florida Citrus Mutual Triangle (1990). Mutual crop report

Editor: V. Meentemeyer shows freeze impact. March 30, 1990; continued April 6 , 1990

Florida Crop and Livestock Reporting Service (undated). Freezes 1886 through 1967 and brief statement of citrus damage. Florida Crop and Livestock Reporting Service, Orlando

Florida Crop and Livestock Reporting Service, biennal series (1980-88). Florida agricultural statistics: commercial citrus inventory. Florida Crop and Livestock Reporting Service, Orlando

Florida Grower and Rancher (1986). FG\&R survey shows favorable outlook for citrus. Florida Grower and Rancher (April): 29-34

FmHA (Farmers' Home Administration) (1985). Instruction 1945-D, Emergency loans for citrus grove rehabilitation and/or reestablishment, Exhibit D, Revision 1 (November), 3. FmHA, Gainesville

Freund, R. J. (1956). The introduction of risk into a programming model. Econometrica 24: 253-264

Gunter, D. L., Fairchild, G. F. (1985). The future of the Florida orange industry. Proc. Florida State Horticultural Soc. (Paper No. 23) 98: 70-74

Markowitz, H. M. (1970). Portfolio selection: efficient diversification of investments. Yale University Press, New Haven

Miller, K. A. (1988). Public and private sector responses to Florida citrus freezes. In: Glantz, M. H. (ed.) Societal responses to regional climatic change: forecasting by analogy. Westview Press, Boulder, p. 375-405

Miller, K.A., Glantz, M. H. (1988). Climate and economic competitiveness: Florida freezes and the global citrus processing industry. Climatic Change 12: 135-164

Muraro, R., Fairchild, G. (1985). Economic factors affecting postfreeze production decisions in the Florida citrus industry. Proc. Florida State Horticultural Soc. 98: 65-70

Powe, C., Langham, M. (1980). Toward a policy testing model for the Florida orange industry. Tech. Bull. 815. Institute of Food and Agricultural Sciences, University of Florida, Gainesville

SBA News (1985). SBA declares disaster area. SBA News, No. 85-14 (March): 1-2

Selley, R. (1984). Decision rules in risk analysis. In: Barry, P. J. (ed.) Risk management in agriculture. Iowa State University Press, Ames, p. 53-67

Taylor, J. G., Stewart, T. R., Downton, M. (1988). Perceptions of drought in the Ogallala Aquifer region. Environment and Behavior 20 (2): 150-175

US International Trade Commission (1983). Frozen concentrated orange juice from Brazil: determination of the commission in Investigation No. 701-TA-184 (final) together with the information obtained in the investigation. Publ. No. 1406, USITC, Washington, D.C.

Manuscript first received: May 30,1990

Revised version accepted: July 30, 1990 